\title{
INTRODUCTION TO SECOND EDITION
}

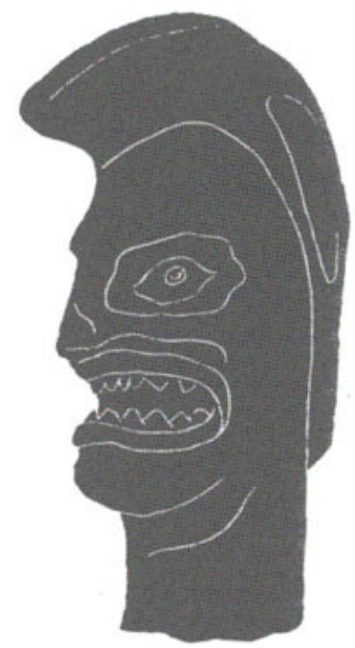

Hawaiian Legends in English: An Annotated Bibliography, by Amos P. Leib, appeared in 1949 as one of the first publications of the fledgling University of Hawaii Press. Its value to readers and researchers in Polynesian mythology was immediately recognized-especially its pioneer contribution to the history of translation of Hawaiian legends and its annotation of about one thousand works ranging from scholarly monographs to retellings for children. C. R. H. Taylor, dean of Pacific bibliographers, in a highly favorable review, wrote: "There is no doubt that for the student of folklore or of Hawaiian history, tradition, and legend, it must simplify almost any approach." The only adverse comment on the original volume was the remark that it unfortunately lacked the "subject approach." However, the annotations were not primarily designed to direct one to gods or monsters, persons or places, but to estimate the value of each source. Anyone desiring to find, say, a legend about a phantom rooster at Waikiki can locate listings in several indexes of books and periodicals such as are found in the Reference Bibliography of the Supplement. These indexes, however, do not annotate any items. The Leib approach is designed to help the researcher to discover the level, style, and authority of a writer before reading his or her treatment of a subject.

During the past thirty years, a surprising amount of activity has gone forward in the translating and retelling of the appealing, age-

${ }^{1}$ C. R. H. Taylor, in Jour. Polynesian Soc., 59 (June 1950), 197-198. 
old stories from Hawaii Nei. And the demand for authentic, wellwritten legends has exceeded the supply. Librarians are besieged daily with requests for more and more stories drawn from the rich lore of oral literature. Enterprising publishers have tried to fill the need by reprinting volumes of ancient legends of greater or less worth. The appetite of children for exciting folklore is not sated by the availability of illustrated-and sometimes moralizing-little books retelling favorite stories from the past. Schools and universities give courses not only in Hawaiian history but in Hawaiian folklore. More than three million people from around the world visit the State of Hawaii annually, and most of them seek at least a glimpse of the exotic island literary past. The Polynesian delight in animating every cloud, hill, rock, and animal is echoed in the habit of tour-bus drivers of inventing amusing "legends" while driving up Nuuanu Valley to the top of the Pali. Magazine writers, apparently, can always sell a version of a tale of the menehune tribe of dwarfs or the naupaka half-flower, and few guide books or advertising brochures omit some reference to Maui the demi-god or Pele the volcano goddess. The rise of "ethnic studies" and a deep concern among those of Hawaiian ancestry to examine anew their cultural roots has aroused a demand for accounts of Hawaiian heroes and noble ancestors. The need for an updating of Amos Leib's fine book, to cover contributions of the past thirty years, has thus become pressing. No less than four hundred annotated works have accordingly been added in the Supplement to the first edition. A number of the references annotated will be of interest to anyone seeking information on pre-Captain Cook culture in the Hawaiian Islands. No fewer than five hundred different authors are represented in this bibliography-indeed a surprising number to have written on a topic so exotic as Hawaiian legends.

Amos Leib concluded his thirty-page survey of the important translators of Hawaiiana by attempting to foresee future activity in this area. He rightly noted in 1947 that the number of people qualified to undertake new translations was decreasing, and that the greatest single source of untranslated legends was the vernacular newspapers, on which Mrs. Mary K. Pukui and others were then working. He also felt that the greatest opportunity to put Hawaiian mythology into English literature would be in retelling the old legends to new audiences. However, he was naturally unable to predict the continued labors of known translators or the rise of later scholars skilled in the nuances of making new versions or correcting old ones. And he certainly could not have anticipated the outpouring of retellings of stan- 
dard stories in magazines, books, and leaflets. Leib's goal, stated on page 37 below, of listing even passing mention of some incident of a legend-" "one or two sentences"- has had to be abandoned in the Supplement. Likewise, no attempt has been made to keep up with the flood of references to Kamehameha I, a historical rather than a legendary figure. The names of book publishers, omitted in the first edition, however, have been added to entries in the Supplement to provide better information to the researcher.

Most of the entries that follow cover publications since 1947. The appearance of several valuable index volumes by librarians since that date-such as several listed in the Reference Bibliography of the Supplement-has enabled me to discover a number of items that were missed by Leib when he laboriously leafed over all the pages of some thirty newspapers and periodicals, seeking even casual references to Hawaiian legends. It is now easier for the researcher to trace most of the references to a given figure or location by using these indexes-which, however, are not annotated and lack the value judgments of the Leib method.

\section{RECENT TRANSLATORS}

Among developments that have occurred during the past thirty years, in the area of translating and publishing Hawaiian legends, is the continued activity of some translators and the emergence of others. Mary K. Pukui, Caroline Curtis, and Katharine Luomala have continued their careers, and later workers include such translators as Samuel H. Elbert, Dorothy B. Barrère, Alfons L. Korn, Jean Charlot, Rubellite Kinney Johnson, Charles W. Kenn, Esther Mookini, Bacil F. Kirtley, and half a dozen students from University of Hawaii classes in the Hawaiian language.

Mrs. Pukui is clearly the foremost authority on the language and literature of the early Hawaiians. She has been honored as a "living treasure" for her untiring services not only as an author in her own right but as a collaborator or consultant on projects initiated by half a dozen other authors. Her name is foremost not only on the covers of the definitive Hawaiian Dictionary and the Pocket Hawaiian Dictionary based upon it, but also on that of the valuable Place Names of Hawaii, which contains many notes on legendary influences on nomenclature. She collaborated with Caroline Curtis on four volumes of retellings of legends for young people, based on standard authorities. Some further information about her life can be found in a bio- 
graphical article published in $1958 .^{2}$ She was born Mary Abigail Kawena Wiggin on April 20, 1895, at Kau, Hawaii, where her father, Henry Nathaniel Wiggin, was head foreman of the Hutchison Plantation. He was a member of a family of Salem, Massachusetts, seafarers, and Dr. Leib was charmed to learn that Mary Kawena was a descendant of the seventeenth-century poet Anne Bradstreet, the first American woman to devote herself to literature. The child's mother, Mary Paahana Kanakaole, a pure-blooded Hawaiian whose parents were medical kahunas, was born to a chiefly family prominent before the introduction of Christianity. The child's maternal grandmother, trained early by her father, was a skilled chanter of ancient meles. Luckily for Hawaiian literature, Mary Kawena spent her first nine years with this lady as a punabele daughter, absorbing the lore of the south Hawaii countryside and listening to her tutu utter chants to Pele. In later years, "Kawena" studied the ancient hula under famed dancers and was, in turn, to teach others such as Iolani Luahine and Jean Erdman. She received some schooling in Honolulu, but did not graduate from the Hawaiian Mission Academy until the age of twenty-seven. At nineteen she married Kalolii Pukui and was widowed in 1943, during World War II, when she served on the home front by working with a camouflage corps. From the age of fifteen, however, when she began collaborating with Laura Green in translating Hawaiian legends and history, Mary Kawena has been a generous and fruitful source of Hawaiiana. For almost half a century she has been associated with the Bernice P. Bishop Museum in Honolulu, and staff members and others have turned to her for information on a dozen areas of study. The former director of the Museum, Dr. Alexander Spoehr, rated her as "the outstanding scholar of Hawaiian ancestry.'

Another scholar who has become more prominent in Polynesian folklore in the past three decades is Dr. Katharine Luomala. She was born in 1907 of Finnish parents in the city of Cloquet in northeastern Minnesota, and went through high school there. She followed an older sister to California and, despite the hardships of the depression years, obtained the bachelor's degree in anthropology from the University of California at Berkeley. Through her sister she had become acquainted with Miss Annie Alexander of a kamaaina family in Hawaii, and this lady's sponsorship led Katharine further into Poly-

${ }^{2}$ Jeanette Lam, “Mary K. Pukui: Words Are Her Business," Par. Pac., 70 Jan. 1958), $24,32$. 
nesian studies, which chimed well with her field research in American Indian culture. In the summer of 1934 , as an aide to Dr. Martha Warren Beckwith, Katharine began a long association with the Bishop Museum, where she met Mrs. Pukui. After obtaining her doctorate in anthropology at Berkeley in 1936-her dissertation was entitled "Maui the Demigod: Factors in the Development of a Polynesian Hero Cycle" - she worked for two years in Honolulu under a joint Bishop Museum-Yale University fellowship, further steeping herself in Polynesian folklore. Additional study on the mainland precluded the possibility of a faculty post, and the war years were spent in interviewing and writing reports for the government. She began in 1946 a career at the University of Hawaii that also included a continuing association with the Bishop Museum. In an excellent biographical account by a colleague, Dr. Leonard Mason, prefacing a festschrift honoring Dr. Luomala, many details are given concerning her contributions "as teacher, researcher, field worker, writer, administrator, editor, and traveler."'3

A third prominent scholar, interested in language problems but also adept at literary study, is Dr. Samuel Hoyt Elbert, another "living treasure" and Professor of Pacific Languages and Linguistics at the University of Hawaii until his retirement. Born in Des Moines, Indiana, on August 8, 1907, he earned an A.B. at Grinnell College in 1928 and a B. Lit. at Columbia in 1931. He wandered for some years among the islands of the South Pacific and served as a lieutenant commander in the United States Naval Reserve in World War II. Elbert came to the University of Hawaii in 1949 and completed a doctoral degree at the University of Indiana the following year. Since that time he has done fieldwork in the Pacific islands and has published several dictionaries and monographs. He is also the collector, with Noelani K. Mahoe, of Na Mele o Hawai' $i$ Nei: One Hundred and One Hawaiian Songs, authoritative texts and translations, as well as comments on poetic vocabulary and an analysis of Hawaiian structure and symbolism in lyrics. A teacher of the Hawaiian language, Elbert worked with Mrs. Pukui to produce several editions of the $\mathrm{Ha}$ waiian Dictionary and Place Names of Hawaii, and he produced texts on Conversational Hawaiian and Spoken Hawaiian. His most recent publication (with Mrs. Pukui) is Hawaiian Grammar. His outstand-

${ }^{3}$ Adrienne L. Kaeppler and H. Arlo Nimmo, eds., Directions in Pacific Traditional Literature (Honolulu: Bernice P. Bishop Mus., 1976), Pp. 1-58, includes bibliography of publications. 
ing work as editor was Selections from Fornander's Hawaiian Antiquities and Folklore. In 1960 he made an illuminating comment on Hawaiian legends in an excellent article:

Hawaiian stories contain much poetry and wit and a certain tough realism. ... The literature is rich and subtle. Every reading reveals new insights and new invitations to psychological interpretations. Hawaiians developed their literature to a high degree of sophistication and beauty apparent to those who know something of the old culture, who are willing to gloss over the dullish places, and to read in Hawaiian and ponder over what lies beneath the words now sparkling, now sug. gesting commercials. ${ }^{4}$

Information is also available concerning Caroline Curtis, prominent reteller of legends and recorder of stories.' She was born in Michigan and majored in history at Mount Holyoke College. She taught in several mainland schools before coming to Honolulu to instruct the fifth and sixth grades at Hanahauoli School. After fifteen years she retired and then went to teach at The Kamehameha Schools, where she began collaborating with Mrs. Pukui on four volumes of legends to be told to children. Her work as an oral recorder of Hawaiian tales is mentioned below.

\section{FURTHER DEVELOPMENTS}

Aside from the continued translation by established scholars, what have been some other developments in the area of producing and publishing Hawaiian legends in English during the thirty years since Amos Leib saw his volume published?

First is an increasing concern with translating fugitive material such as that found in newspapers, and in revising or correcting previous works. In recent years the study of the Hawaiian language has had a revival, even though fewer persons speak it as a first tongue. Little material on legends in Hawaiian has been left unscrutinized by able critics.

A not unexpected result of this activity is the uncovering by recent translators of some evidence of corruption in sources previously

4 Samuel H. Elbert, "The Unheroic Hero of Hawaiian Tales," Jour. Polynesian Soc., 69 (Sept. 1960), 266-275.

s Mildred Osmundson Gordon, "The Story of a Story-teller: The Life of Caroline Curtis," in Makers of Destiny-Hawaiian Style (Honolulu: Delta Kappa Gamma Society, 1969). 
thought to be unflawed by non-Polynesian intrusions. Among these sources are works by Abraham Fornander and S. N. Kamakau that incorporate Biblical stories and inventions into the body of presumably authentic Oceanic myths. Dr. Bacil F. Kirtley, commenting on the fascinating monograph The Kumuhonua Legends by Dorothy B. Barrère, remarked:

Though scholars like Dixon, Williamson, and Beckwith have indicated repeatedly that Polynesian converts to Christianity introduced Biblical elements into their inherited mythology, Barrère, by concentrating upon this redactional activity itself, suggests the prevalence of the phenomenon. Perhaps the most audacious improvisations on Mosaic legendry were those created from 1865 to 1870 by the Hawaiians Kepelino and Kamakau, and naively perpetuated by Abraham Fornander in the "Kumuhonua legends." In these plagiarisms, a triad of deities (Kane, $\mathrm{Ku}$, and Lono) create the first man from red clay and the first female from his rib. A mo'o, or reptile, contrives the primal couple's downfall and "the large white bird of Kane" ejects them from Paradise. Led by the marplot Kanaloa, a band of angels revolts against the ruling powers and is banished to "uttermost darkness" and Kanaloa's futile attempt to create a human being introduces death into the world. A world flood is caused by mankind's wickedness, but the patriarch Nuu survives this catastrophe. Further, the Abraham-Isaac story is imitated, as are accounts of the Hebrew escape across "the Red Sea of Kane" and of the career of Joseph-his abandonment in a pit, and his later successes in a foreign land. ${ }^{6}$

Further comments on this development may be found in the annotations under Barrère, The Kumuhonua Legends.

Another development, perhaps not so praiseworthy, is the invention of legends to suit the aims of some publishers. An example of this process is described in a newspaper article. ${ }^{7}$ Challenged by children on the lanai of the Makaha Country Club to tell a story about the surrounding Oahu valley, Pilipo Springer extemporized a tale that later was revised for use as a press handout. Robert Goodman, seeking to print an illustrated book for children, was unable to find a legend of Makaha in any library but learned about the publicity story. In a session with his advisers, Ruth Tabrah and Robert Spicer, he used "selective creativity" and produced Makaha: The Legend of

${ }^{6}$ Bacil F. Kirtley, “'Some Extra-Oceanic Affinities of Polynesian Narratives,” in Directions in Pacific Traditional Literature, pp. 217-218.

7 Murry Engle, “An Instant Folktale Like the Real Thing," Hon. Star-Bull., May 29, 1974, p. D-1. 
the Broken Promise, an invention with a suitable moral. Several other books, such as those by Guy and Pam Buffet, follow this same method. As Goodman explained to the reporter: "We try to fill loopholes in the story in a culturally credible way, enriching it with phrases, insights, interrelationships. Anyone reading the story thus can be instructed in early Hawaiian culture. At the same time, the story will ring true to anyone who knows the culture well. It honors countless subtle relationships that existed."

In contrast, one may quote Katharine Luomala's idea of the value of myth or legend in the serious study of a culture: "To a specialist in mythology, a myth incident or episode is as objective a unit as an axe, and the differences and similarities of these units can be observed equally clearly and scientifically." 8 Is not this manufacturing of "legends" without labeling them fiction a more serious form of corruption that the well-meaning Christianizing of the ancient Polynesian heritage by Kepelino and Kamakau? Our concern with the source of a legend indicates that authenticity is worth preserving. Legends are a kind of rough history. They originated in an honest effort by a people to explain their environment to themselves. The trend toward contriving stories that masquerade as authentic but lack or distort the old Polynesian spirit works, I believe, an injustice to a great culture.

Another development, made possible by the availability of taperecording techniques, is the recounting of legends by skilled storytellers. Caroline Curtis, during her work at The Kamehameha Schools, made recordings of some fifty of her favorite legends, including tales of Maui, the menehune tribe, Pele, sharks, and others.9 Alice Kamokila Campbell, daughter of a leading kamaaina family, produced an album-Legends of Hawaii (Rainbow Record and Publishing Company, 1957)-that gives an idea of the performance of the chanter of moolelo and kaao of Hawaii Nei. More activity in recording authentic tales should be encouraged, to meet the expectations of the aurally-minded generation of young people today.

Finally, legends have even been used to justify the halting of a federal highway through the Koolau Range on the island of Oahu. The Secretary of the Interior, in a judgment based partly on notes about the legends of Moanalua Valley, has declared that the historic value

8 From Luomala's application for the Bishop-Yale Fellowship in 1938.

9 Selected Hawaiian Legends, Kamehameha Schools, 1964. Seven reels of seveninch tape. Synopsis and bibliography prepared by Helen Gokan and others. 
of this proposed route precludes its use as a freeway. Even in the 1970 's, the power of legend should not be discounted!

\section{A PERSONAL NOTE}

My efforts in updating Amos Leib's 1949 volume on Hawaiian legends are, in one sense, a memorial to a long-time friend.

Amos Patten Leib was born in New London, Connecticut, on December 8, 1917, and died while on sabbatical leave from the University of Hawaii in Old London, England, on January 3, 1977, aged barely fifty-nine years.

I knew Amos over a period of more than thirty years. I came to the University of Hawaii at Manoa in the autumn of 1944, during World War II, when we had a nightly curfew and the campus was dotted with wooden underground bomb shelters instead of concrete highrises. My teaching assignment included the task of advising three graduate students who were writing theses for the master of arts degree. One was Amos Leib. I learned that he had obtained a bachelor of science degree from Haverford College in 1938 and had taught at Iolani School in Honolulu for three years before joining the faculty at Punahou School in 1941. For his pleasure he had taken courses at the University until it was discovered that he could obtain the master's degree if he completed the thesis requirement. Together we chose the topic of preparing an annotated bibliography of all the published writings in English concerning Hawaiian myths and legends. With his typical thoroughness he spent several years on this labor, but the result was an M.A. awarded in 1947 and a book published by the University of Hawaii Press-Hawaiian Legends in English-in 1949. Thereafter I recommended this volume as the handbook for anyone at all concerned with studying the early literature of the Hawaiian Islands.

For his abilities Amos had been given an instructorship in the Department of English in 1945 and had begun a career that earned him a full professorship in 1971. During this career he taught a number of courses, ranging from literature of the Middle Ages to literature of the islands of the Pacific Ocean. To qualify for promotion he spent two years at Tulane University in New Orleans, where he and Loelhis special name for his wife, Edna Lee Pegram Leib-went through the usual stringent times, aided by temporary teaching jobs and scholarships. Amos' Ph.D. was awarded in 1963; his dissertation was on Nathaniel Hawthorne. Dozens of his teaching colleagues in the. 
Department of English recall his service with them on many projects, and hundreds of former students remember him as a wise and witty teacher and scholar.

For thirteen years Amos Leib held an official post as University Marshal, organizing and presiding over commencement ceremonies. His main community service came in the form of acting in various community theaters and singing as a member of the Gleemen of Honolulu for almost four decades. He continued his interest in writing and, in addition to the two theses and critical articles, in 1972 he published The Many Islands of Polynesia. A lighter kind of writing is represented by his annual New Year's letter, which gave him free scope for his humorous quips and accounts of travels to many islands around the world. But now, along with his beloved author Robert Louis Stevenson: "Home is the sailor, home from the sea,/And the hunter home from the hill."

During Dr. Leib's sabbatical leave, illness made it difficult for him to continue the revision of Hawaiian Legends in English he had begun in Honolulu, and even the British Museum lacked the full facilities needed to update this work on a literature created many meridians west of Greenwich.

I acknowledge warmly the invitation of Mrs. Leib to complete the task of preparing a second edition, as well as her cooperation in obtaining publication. I have retained wherever possible Dr. Leib's comments on a number of the four hundred entries in the Supplement. Any errors or omissions are, of course, my responsibility.

I must laud the informed services of the libraries of Honolulu-in particular, the staff of the Hawaiian and Pacific Collection of the University of Hawaii Library, whose stacks I have haunted for more than three decades; the Hawaiian shelves contain as many as thirty thousand bound volumes along with much unbound material, and this work could not have been attempted without access to the library's treasures. And again I appreciate the skills demonstrated by the people at The University Press of Hawaii, with whom I have previously published six volumes.

Emeritus Professor

A. GRove DAY

University of Hawaii

June, 1979 